\title{
On the Technology and Management of Substation Maintenance
}

\author{
Feng Wei, Lei Zhipeng, Wu Jian \\ Yingkou Power Supply Company of National Grid Liaoning Electric Power Co., Ltd \\ jkweiz@sina.com
}

Keywords: substation equipment; condition-based maintenance

\begin{abstract}
With the development of national economy, China's needs for electricity are growing and the requirements on quality is also becoming stricter on the power system security, stability and economic operation. Diagnosis of the state of equipment is mainly based on statistical analysis of large amounts of data. But with the development of computer technology and artificial intelligence, a diagnostic equipment is formed like an expert system, replacing the past practice by recognizing equipment malfunction by years of data on tests, operations, maintenance and so on. Comparative analysis is done by repeated calls of accident records. It becomes more accurate and reliable to introduce and apply advanced technologies of condition-based maintenance and management into insulation diagnosis of electrical equipment.
\end{abstract}

\section{Two development stages of maintenance modes}

The developmental history of maintenance modes can be concluded mainly by two stages: corrective maintenance and preventive maintenance.

\section{Corrective Maintenance}

Corrective maintenance, also known as post-maintenance, is based on the occurrence of functional failure in the equipment. It is the earliest mode of maintenance. Under this mode, maintenance is only carried out when the equipment fails to work, thus leading to production delay, huge losses and maintenance cost. Therefore, this mode is not effective enough.

\section{Preventive Maintenance}

Maintenance modes of power system changes with the development of power industry. There are three maintenance modes according to technical conditions and targets for maintenance: the first is condition-based maintenance (CBM) . This mode requires regular check on the status of the equipment by means of inspection, examination, testing, etc.. A reasonable maintenance plan is made by evaluating the status of the equipment. If possible, maintenance plan can also be made according to status values measured by online monitoring and live detection, etc. to achieve maximum efficiency and reliability. The second is regular maintenance. When there is few equipment of similar quality, the best maintenance mode is to check on the equipment after a fixed time interval or after a certain operational times. With expansion of the grid size, labor and material support will become insufficient if a regular maintenance mode is remained. The third is reliability-based maintenance. While status maintenance mainly considers the status of a single equipment, reliability-based maintenance takes the whole condition of power grid into consideration, such as the equipment risks and maintenance cost.

\section{Application of Condition-based Maintenance methods on Substation Equipment \\ Condition-based Maintenance of Relay Protection Equipment}

An analysis on the accidents and failures of relay protection equipment can help make the maintenance methods more accurate. Take the statistical analysis on accidents and failures of microcomputer protection as example. Since accidents caused by interference are not reflected in operation, they can never be detected by conventional test methods, but be reduced to the minimum in equipment selection and production tests. Defects of the equipment itself lead to more incorrect 
actions, which takes a large proportion of the reason. For example, directional element refuses to work when a fault current 58A is applied on the protective equipment, which is generally not included in annual maintenance. Most of such risks can hardly be detected by conventional test methods in regular maintenance. Annual maintenance also does not include tests on the protection failure when third harmonic fault value is removed.

For most malfunctions caused by secondary circuit, there are five points worth noting when maintenance principles or methods are decided: firstly, the target equipment of condition-based maintenance should be assessed according to its condition by means of inspection, second through-flow test, transmission with switches, standard calibration, etc., so as to determine the specific maintenance plan. Secondly, strengthen the executive enforcement of anti-jamming measures in microcomputer protection. Thirdly, it is applicable to adopt condition-based maintenance. Fourthly, analyze the main defects or possible risks found in regular maintenance. The focus of microcomputer protection maintenance should be shifted from fixed value recheck and protective function logic identification to maintenance on circuit and auxiliary equipment. Fifthly, strengthen professional inspection of relay protection equipment to make protection drive test with the combination of defect treatment.

\section{Condition-based Maintenance of High-voltage Switchgear}

According to the current operation situation of common switchgear equipments in China, classified statistics of switchgear defects and analysis of typical faults, four laws can be summed up in the faults of high-voltage switchgears. First, while the fault rate of some domestic SF6 switchgears is relatively higher, the overall performance of foreign SF6 switchgears is more stable. As the low pressure alarm of SF6 works in a gradual process and the switchgear can do self detection, it is still worth of development under control. Secondly, for $6 \sim 35 \mathrm{kV}$ vacuum circuit breakers, temporary repairs couldn't exert enough control over it as the malfunctions are generally caused by mechanical failures. Therefore, it is necessary to strengthen management over switches with continuous operation and vacuum tests on vacuum bubbles to check on the status of equipment in time. Strengthen check and adjustments over controlling circuit devices and strictly control mechanical operation times, doing maintenance in time before the operation reaches its limit. Conduct selective rotated simulation tests before thunderstorm season every year. Thirdly, due to the capacity limit and insufficient sealing performance of oil circuit breakers, oil leakage of the switch body still takes the dominate place. About $96 \%$ of such switch malfunctions is due to failure to check on the switch times. Fourthly, major repair can be done when mechanical operation times reach the mechanical lifetime of the product if the overall vacuum switchgear equipment is in good condition. On the one hand, conduct major repair when the switch contact reaches its electrical lifetime, or when switch fault current times reach the boundary value of technical requirement. On the other hand, targeted maintenance should be conducted when switchgears begin to affect the normal operation of equipment, and circuit resistance and moisture tests should be carried out every three years.

\section{Process Management of Condition-based Maintenance}

Condition-based maintenance in the true sense costs the least and focuses on the whole process management of condition-based maintenance so that the operation of equipments keeps the maximum of reliability. Conducting regular detection, regular elimination and accelerated depreciation can improve equipment reliability if the operation is unstable or uncontrollable. As to operational maintenance of some non-essential equipments, rely heavily on monitor means to forecast the final operation extent and conduct preventive maintenance.

\section{Maintenance Model Management of Transmission and Transformation Equipment}

The commonly adopted mode in China is condition-based maintenance as dominant and diagnostic maintenance as supplementation, instead of the conventional maintenance modes. The 
past integrated mode of maintenance and operational management is divided into two separate departments, whose tasks are reallocated in accordance of the principle "specific conditions based, achieve recovery once repair begins" as a solution to the responsibility confusion between substation maintenance and test maintenance. Electrical maintenance is responsible for operation and management of equipment, temporary and major repair and routine maintenance of secondary electrical equipment, and temporary and major repair of mechanics and primary electrical equipment; the test group is responsible for tests and evaluations of primary and secondary electrical equipment, improving the team members' technical capacity and establishing new maintenance concept, so as to achieve a retrenched and better institution. Taking condition-based maintenance as the basis and corrective maintenance and preventive maintenance as supplementation, the maintenance plan will help the office to make responsibilities more clarified and simplistic, developing a mixed maintenance mode of equipment operation while trying to achieve the target of minimum economic consumption.

\section{Change Concepts and Strengthen Management of Condition-based Maintenance}

The fixed maintenance period does not change with the equipment's operational condition, situation, liability and equipment type. Pure planned maintenance, a management mode of equipment maintenance adopted under planned economic management model in China, is no longer suitable for the contemporary society development. One should break through the old concepts and ideas of fixed maintenance period under pure maintenance mode completely. It is necessary and imperative to build up a hybrid maintenance mode by combining condition-based maintenance with preventative maintenance and corrective maintenance.

\section{Trying to Promote Condition-based Maintenance on the Base of Early Practice}

Currently, the maintenance system reform is an important issue for grid. There have been some condition-based maintenance work of "primary stage" being carried out in the operational management of certain equipment in China. For example, since major repair takes place every 10 years, the adoption of condition-based maintenance can help prevent the further expansion and worsening of oil seepage problems in main transformer oil conservator and gas permeability relay. Integrated automation and dispatching automation can also be used to guarantee condition-based maintenance by monitoring the operational condition of substation equipment through dispatching operation duty system. 66KV transmission lines is relatively short and each substation supplies electricity by double power. Among them, Qidaoquanzi sub-transmission lines is by steel tube poles and the wire model is LGJ - 150 that can guarantee the liability of power. The overhang composite insulator of Changbao 66KV power transmission line help reduce pollution problems of Changbao cement plant. Based on testing results in recent years, condition-based maintenance period of the equipment has been extended into every two years for the best, which can also help save a lot of manpower and material resources.

\section{Conclusion}

Power production enterprises are facing the dilemma of ensuring a certain degree of equipment availability and reliability and at the same time reducing cost of maintenance. The occurrence of failure in electricity system equipment does not only bring great damages to the equipment, but imposes great threats on the normal production of many industries and people's living. The highest development goal of power supply companies is to enhance power production efficiency, improve the level of automation, ensure reliability of power supply, and reduce the occurrence of malfunction and equipment spoilage. As the hub for electric power transmission and distribution, substation is the main component in electric power network. Therefore, it is crucial to ensure the safe and stable operation of substation equipment. Condition-based maintenance is preventive maintenance based on condition information provided by equipment monitoring, diagnosis and assessment, or in order words, preventive maintenance according to the operational condition and healthy status. 


\section{References}

[1] Tang Qi. Discussion on Technology of Substation Equipment Maintenance and Repair Considerations [J]. Telecom Power Technologies, 2011-11-25.

[2] Li Hai. Analysis of Substation Maintenance Technology and Its Matters Needing Attention [].Guangdong Science \& Technoloy.2012-04-25

[3] Wu Hao. The Issues in Substation Maintenance [J] Heilongjiang Science and Technology Information .2011-12-25

[4]Ma Ye. On the Issues in Substation Maintenance [J]Science \& Technology and Enterprises. 2011-08-06

[5] Liu Yunlong. On the Safe Operation and Management of Integrated Automatic Substation [J]. Non-State Running Science \& Technology Enterprises, 2010(12). 